\title{
BERNARD GAINOT, La révolution des esclaves. Haiti,
}

\section{3-1803}

\section{Roberto Ferraroni}

\section{(2) OpenEdition}

\section{Journals}

\section{Edizione digitale}

URL: http://journals.openedition.org/studifrancesi/15973

DOI: 10.4000/studifrancesi. 15973

ISSN: 2427-5856

\section{Editore}

Rosenberg \& Sellier

\section{Edizione cartacea}

Data di pubblicazione: 1 décembre 2018

Paginazione: 545

ISSN: 0039-2944

\section{Notizia bibliografica digitale}

Roberto Ferraroni, «BernaRd GaInot, La révolution des esclaves. Haiti, 1763-1803», Studi Francesi [Online], 186 (LXII | III) | 2018, online dal 01 janvier 2019, consultato il 06 janvier 2021. URL: http://

journals.openedition.org/studifrancesi/15973 ; DOI: https://doi.org/10.4000/studifrancesi.15973

Questo documento è stato generato automaticamente il 6 janvier 2021 .

\section{(2) $(\mathcal{Q} \Theta \Theta$}

Studi Francesi è distribuita con Licenza Creative Commons Attribuzione - Non commerciale - Non opere derivate 4.0 Internazionale. 


\title{
BERNARD GAINOT, La révolution des esclaves. Haiti, 1763-1803
}

\author{
Roberto Ferraroni
}

\section{NOTIZIA}

BERNARD GAINOT, La révolution des esclaves. Haiti, 1763-1803, Paris, Vendémiaire, 2017, 285

pp.

1 Bernard Gainot, professore associato all'Université Paris 1, è studioso ed esperto di storia moderna, specializzato nella storia francese e coloniale del XVIII e XIX secolo. In questo saggio mette a disposizione del lettore la sua profonda conoscenza delle complesse e inevitabilmente drammatiche dinamiche che hanno portato alla dichiarazione di indipendenza di Haiti il $1^{\circ}$ gennaio 1804 . Nello specifico, affronta con minuziosa attenzione, come si evince già dal sottotitolo, i 40 anni di questo processo che sono stati testimoni di lotte sanguinose combattute dalla popolazione locale contro la madrepatria che hanno portato, attraverso un ingente tributo di sangue, alla liberazione dell'isola dal dominio francese.

2 Il saggio inizia con una rapida introduzione in cui l'autore presenta il periodo storico immediatamente successivo alla Guerra dei Sette anni, come un periodo in tumulto, instabile, attraversato da cambiamenti epocali come la rivoluzione americana, quella francese e, appunto, quella della colonia haitiana. Dopo questa prima sezione, il saggio si sviluppa in dieci capitoli che ci illustrano in modo molto dettagliato e preciso gli eventi che si sono susseguiti nel quarantennio "esplosivo" dell'isola. Un'analisi, quella di Gainot, che illustra le strategie militari e politiche dei protagonisti di quegli anni.

3 Singolare, e a tratti destabilizzante, è la scelta dell'autore di non seguire un ordine strettamente cronologico: il lettore si trova spesso trasportato avanti e indietro nel tempo, rischiando di perdere l'orientamento nella lettura. Tuttavia, l'abilità di Gainot nel richiamare alla mente date e avvenimenti già incontrati nel corso della lettura, permette di non perdere mai completamente di vista lo sviluppo degli eventi. Senza 
contare l'ultima sezione del libro, Annexes, che accorre in aiuto del lettore presentando una cronologia precisa dei fatti salienti del periodo.

È affascinante notare con quanta passione Gainot scrive il suo libro, riuscendo a districare i nodi di un periodo storico decisamente complicato e presentando le ragioni dell'una e dell'altra parte in modo chiaro e imparziale. Anche il lettore totalmente estraneo all'argomento, che poco conosce di politica e tecniche militari, si ritrova a tal punto immerso nel clima dell'epoca da riuscire a percepirne le paure, le ansie, le speranze. L'autore scende anche nel dettaglio di quelle che sono state le strategie militari scelte dai comandanti, descrivendo i vantaggi della conquista di quella città o di quell'avamposto: anche il lettore più inesperto in campo militare riesce a cogliere l'importanza della tattica adottata degli eserciti contrapposti. Estremamente utili per la comprensione delle mosse operate durante il conflitto sono anche le cartine geografiche collocate negli Annexes, che aiutano il lettore non soltanto a conoscere l'isola da un punto di vista geografico, ma a comprendere gli spostamenti delle forze in gioco sul finire dell'Ottocento.

5 Una considerazione particolare va appunto fatta anche sulle forze scese in campo, presentate con attenzione dall'autore. Indubbiamente, viene dato ampio spazio agli schiavi, spesso provenienti dal continente africano: è da loro che parte la trattazione dell'argomento. Si viene quindi a conoscenza di coloro che sono stati il vero cuore della rivolta. Ma nello stesso tempo ci vengono presentati anche i coloni francesi che a un certo punto hanno deciso di ribellarsi alla madrepatria e di opporsi al suo predominio. Di notevole interesse sono anche i ritratti di militari e politici descritti da Gainot, come Toussaint Louverture, Etienne de Laveaux e Charles Leclerc, che avvicinano il lettore agli altri protagonisti del conflitto.

Dalla lettura di questo saggio si evince in modo chiaro e indiscutibile la conoscenza approfondita dell'argomento da parte dell'autore, ma anche il suo reale interesse per la storia, una passione che viene trasmessa totalmente al lettore attraverso le sue parole e l'abilità nell'utilizzarle, in modo tale che anche chi non possiede nessuna confidenza con questo tema riesce a comprenderlo senza alcun problema e a immergersi in un periodo storico tanto complesso e ricco di eventi. Il linguaggio scelto da Gainot non è mai complicato, i periodi sempre fluidi nonostante descriva spesso, in modo anche tecnico, strategie politiche e militari articolate. Si tratta di un saggio interessante che riesce a dare un'idea chiara ed esaustiva di quegli anni tanto travagliati che hanno portato una nazione a dichiarare con orgoglio la propria indipendenza. 